International Journal of

BioScience and Applications

\title{
Effect of Fasting Weight Training on Obesity Indicators and Blood Lipids on Korean
}

\author{
Do-Jin Kim* \\ Department of Rehabilitation Sports, Bucheon University, Republic of Korea
}

\begin{abstract}
$^{1}$
Background/Objectives: The purpose of this study was to examine changes in obesity indicator and blood lipids by participating in weight training after maintaining a fasting for 12 hours in obese middle-aged women for 8 weeks. Methods/Statistical analysis: 8-week exercise program was conducted by dividing into 10 people in the fasting weight training group(WG) and 10 people in the control group(CG). PASW 18.0 Statistical programs were used to present the descriptive statistics of the measurement variables. Comparisons of the two groups were analyzed by 2-way ANOVA. Findings: There was a significant difference between the WG and the CG in TG, $\mathrm{TC}, \mathrm{HDL}$ and leptin $(\mathrm{p}<05)$, but there was no significant difference in irisin $(\mathrm{p}>.05)$. Improvements/Applications: The purpose of this study was to examine the effect of fasting exercise on obese middle-aged women. Through this exercise, significant results were obtained in obesity indicator and blood lipid. If future research is conducted through changes in exercise duration and fasting time, meaningful results will be provided.
\end{abstract}

\section{Index Terms}

Fasting weight training, Obesity indicator, Blood lipids, Irisin, Leptin

\footnotetext{
*Corresponding author : Do-Jin Kim

taehab@hanmail.net

- Manuscript received October 15, 2021.

- Revised November 10, 2021 ; Accepted December 1, 2021.

- Date of publication December 30, 2021

(c) The Academic Society of Convergence Science Inc.

2619-8363 @ 2021 IJBSA. Personal use is permitted, but republication/redistribution requires IJBSA permission.
} 


\section{INTRODUCTION}

It is reported that fasting level and obesity-related blood variables are highly correlated. Maintaining a constant feeling of hunger is positive for healthrelated variables[1], and Kim et al[2] shows that exercising in a fasting state promotes lipid metabolism by exercising in a low blood sugar state. Lipid is a major organic substance that composes the living body along with proteins and sugars. In order to generate energy, it was reported that triglycerides are effectively decomposed into glycerol and free fatty acids by lipolysis [3].

Exercise directly stimulates the secretion of growth hormone in the process of promoting the growth of muscle cells and the development of muscle strength, thereby directly increasing the amount and frequency of hormone secretion, Growth hormone secreted during exercise antagonizes with insulin[4]. It promotes the breakdown of fat through fat cells, and has a receptor for growth hormone in fat cells, so it plays a role in reducing fat through fat breakdown by growth hormone.

In addition, it is reported that exercise in the morning fasting state can help in weight control by promoting the mobilization of lipids in adipose tissues due to low blood sugar levels[5].

Adipose tissue in our body can be divided into two types of fat cells, white fat and brown fat, which have different endocrine functions. It plays a role in the secretion of several adipokines[6]. Leptin is an adipokine, a representative substance secreted from adipose tissue, which affects the increase in energy intake related to obesity and plays a role in regulating body weight and satiety[7].

Irisin is one of several factors of myokines secreted from muscles, and myokines are cytokines produced and secreted by muscles[8]. It has been reported that it is possible[9].

Browning refers to the browning of white fat. As the expression of PGC-1a mRNA increases, the expression of FNDC5 mRNA increases, which induces an increase in Irisn and affects the browning of white fat [10]. Irisin expression is caused by the activation of peroxisome proliferator-activated receptor rcoactovator-1a (PGC-1a) and fibronectin type III domain contaning 5 protein (FNDC5), and proton transport chains (transport protons) in the inner mitochondrial membrane of brown adipocytes It activates UCP1 floating in the chain) to increase ATP and generate thermal energy. This in turn leads to weight loss by increasing energy consumption[11].

Therefore, this study aims to investigate the effect of weight training for 8 weeks on middle-aged women on obesity metabolism and blood lipids, and to provide basic data for exercise programs to prevent obesity and cardiovascular risk in middleaged women.

\section{RESEARCH METHOD}

\section{A. Subject of Study}

The purpose of this study was to investigate the effect of fasting weight training on obesity indicators and blood lipids. To this end, an 8-week exercise program was conducted by dividing into 10 people in the fasting weight training group(WG) and 10 people in the control group $(\mathrm{CG})$.

Table 1. General characteristics of study subjects

\begin{tabular}{|c|c|c|c|c|}
\hline Group & $\begin{array}{c}\text { Age } \\
(\mathrm{yr})\end{array}$ & $\begin{array}{c}\text { Height } \\
(\mathrm{cm})\end{array}$ & $\begin{array}{c}\text { Weight } \\
(\mathrm{kg})\end{array}$ & $\begin{array}{c}\text { Fat } \\
(\%)\end{array}$ \\
\hline WG & 51.58 & 160.28 & 64.33 & 32.20 \\
& \pm 3.15 & \pm 3.56 & \pm 2.59 & \pm 1.90 \\
\hline CG & 51.47 & 161.10 & 63.85 & 33.05 \\
& \pm 2.29 & $2.95 \pm$ & \pm 3.05 & $2.24 \pm$ \\
\hline
\end{tabular}

\section{B. Weight Training}

For the fasting weight training, the weight training program was conducted with 12 hours of fasting time. The weight training program consisted of bench press, lying leg curl, bent of barbell curl, bent of lateral raise, leg raise, lunge, squat, etc., including warm-up and cool-down a week for 60 minutes. The exercise intensity continued to be RPE(rating of perceived exertion) $<13$.

\section{Measurement}

Measured variables were irisin and leptin as obesity indicators, and triglycerides(TG), high density lipoprotein cholesterol(HDL), and total density lipoprotein cholesterol(TC) were measured as blood lipids.

\section{Data Analysis}

PASW 18.0 Statistical programs were used to present the descriptive statistics of the measurement variables. Comparisons of the two groups were analyzed by 2 -way ANOVA. The significance level was set to be .05 .

\section{RESUltS}

\section{A. Obesity indicators}

There was a significant difference between the weight training group(WG) and the control $\operatorname{group}(\mathrm{CG})$ in leptin $(\mathrm{p}<05)$, but there was no significant difference in irisin $(\mathrm{p}>.05)$. 
Table 2. Changes in obesity indicator

\begin{tabular}{|c|c|c|c|}
\hline variable & Group & Pre & Post \\
\hline Irisin(ng/ml) & WG & $19.71 \pm 4.40$ & $18.82 \pm 3.78$ \\
\cline { 2 - 4 } & CG & $19.42 \pm 3.64$ & $19.99 \pm 4.07$ \\
\hline Leptin(ng/ml) & WG & $12.88 \pm 4.03$ & $8.17 \pm 3.03 *$ \\
\cline { 2 - 4 } & CG & $13.05 \pm 2.37$ & $12.84 \pm 2.16$ \\
\hline$*: p<.05$
\end{tabular}

\section{B. Blood lipids}

There was a significant difference between the weight training group(WG) and the control group $(\mathrm{CG})$ in TG, HDL, and TC. $(\mathrm{p}<.001)$.

Table 2. Changes in blood lipids

\begin{tabular}{|c|c|c|c|}
\hline variable & Group & Pre & Post \\
\hline TG(mg/dL) & WG & $158.88 \pm 11.50$ & $152.27 \pm 12.35 * * *$ \\
\cline { 2 - 4 } & CG & $162.63 \pm 10.23$ & $163.87 \pm 11.27$ \\
\hline \multirow{2}{*}{ HDL(mg/dL) } & WG & $48.26 \pm 4.26$ & $53.45 \pm 3.75 * * *$ \\
\cline { 2 - 4 } & CG & $49.89 \pm 3.98$ & $49.98 \pm 4.09$ \\
\hline TC(mg/dL) & WG & $202.38 \pm 14.56$ & $193.44 \pm 13.64 * * *$ \\
\cline { 2 - 4 } & CG & $203.23 \pm 12.81$ & $203.77 \pm 13.09$ \\
\hline$* * *: p<.001$ & \multicolumn{3}{|c}{} \\
\hline
\end{tabular}

\section{CONCLUSION AND DiscuSSION}

The purpose of this study was to examine changes in obesity indicator and blood lipids by participating in weight training after maintaining a fasting for 12 hours in obese middle-aged women for 8 weeks.

First, in irisin and leptin, which are indicators of obesity, weight training after fasting showed a significant change in leptin, but did not show a statistically significant change in irisin. However, the average comparison showed a change.

In the obesity index, it was judged to be significant in the change of the weight training obesity indicator after 8 weeks of fasting maintenance.

In the change of blood lipids, there were statistically significant differences in triglyceride, TC, and HDL, and exercise after fasting was judged to represent a significant change in changes in blood lipids.

There was no statistically significant difference in irisin when judging the obesity index in consideration of changes in blood lipids, but it is judged to have significance when considering changes in blood lipids.

Through this, it is judged that fasting exercise shows positive changes in obesity indicatior and blood lipids.

In this study, 8-weeks resistance exercise after 12 hours of fasting maintenance in middle-aged women showed positive changes in obesity metabolism and changes in blood lipids.

It is believed that this played a big role in revealing the treatment effect by actively participating in the resistance exercise program and efforts to maintain the fasting time of the study subjects. In addition, it is considered meaningful research results to show changes in obesity metabolism and blood lipids after a short-term training participation, and based on this, it is considered necessary to obtain more clear research results by broadening the class of subjects and research related to various variables.

\section{REFERENCES}

[1] J. H. Kim, D. J. Kim, S. H. Park. (2015). The study on the relationship between hunger recognition level and obesity variable of elderly women. The Korean Journal of Physical Education, 2015:54(6): 475-483.

[2] C. H. Kim, M. S. Song, S. I. Cho, H. K. Seo, J. H. Choi, B. M. Shin. Research on the effects of fasting on the body. The Korean Academy of Family Medicine, 1994:164:1128-1140.

[3] W. Derave, A. Mertens, E. Muls, K. Pardaens, \& P. Hespel. Effects of post absorptive and postprandial exercise on glucose gulation in metabolic syndrome. Obesity, 2007:15(3):704-711.

[4] M. A. Singh, W. Ding, T. J. Manfredi, G. S. Solares, E. F. O'Neill, K. M. Clements, N. D. Ryan, J. J. Kehayias, R. A. Fielding, \& W. J. Evans. Insulinlike growth factor I in skeletal muscle after weight lifting exercise in frailelders. Am $J$ Physiol, 1999:277(1):E135-143.

[5] W. Derave, Mertens. A, Muls. E, Pardaens. K. \& Hespel. P. Effects of Post-absorptive and Postprandial Exercise on Glucoregulation in Metabolic Syndrome. Obesity, 2018:15(3):704-711.

[6] Fenzl, A., Kiefer. F. W. Brown adipose tissue and thermogenesis. Horm Mol Biol Clin Inversting, 2014:Jul:19(1):25-37.

[7] Irwin, M. L., McTiernan, A., Bernstein, L. Relationship of obesity and physical activity with Cpeptide, leptin, and insulin-like growth factor in breast cancer survivors. Cancer Epidemiol Biomarkers Prev, 2005:14:2881-2888.

[8] Pedersen, B. K. Exercise-induced myokines and their role in chronic diseases. Brain Behav Immun, 2011:Jul:25(5):811-816.

[9] Sinha, M. K., Opentanova, I., Ohannesian J. P., Kolaczynski, J. W., Heiman, M. L., Hale, J., Becker, G. W., Bowsher, R. R., Stephens, T. W., Caro, J. F. Evidence of free and bound leptin in human circulation. Studies in lean and obese subjects and during short-term fasting. J Clin Invest, 1996:Sep 15:98(6):1277-1282. 
[10] Huh, J. Y., Panagiotou, G., Mougios, V., Brinkoetter, M., Vamvini, M. T., Schneider, B. E., Mantzoros, C. S. FNDC5 and irisin in Humans. Metabolism, 2012:61(12):1725-1738.

[11] Novelle, M. G., Contreras, C., Romero-Pico, A., Lopea, M., Dieguez, C. Irisin, two years later. Int J Endocrinol, 2013:246-281. 